\title{
Self-Reported Periodontal Disease: Validation in an Epidemiological Survey
}

\author{
George W. Taylor*† and Wenche S. Borgnakke*
}

Background: Evidence is accumulating to support poor oral health as a risk factor for systemic conditions, including cardiovascular diseases, diabetes control, adverse pregnancy outcomes, and pneumonia. Prohibitive costs for clinical assessment of periodontal disease limit information to assess the prevalence and trends of periodontal diseases in the United States population. However, self-report is used widely to assess economically the population-based prevalence of various medical conditions and health-related behaviors and characteristics.

Methods: The goal of this secondary data analysis was to identify self-report items sufficiently correlated with clinical periodontal disease for use via face-to-face or telephone interviews. Data for analysis were collected for a project focused on oral health that included face-to-face interview items regarding oral health-related self-care, professional care, and barriers; knowledge, beliefs, and attitudes; risk behavior; impact on quality of life; and demographic characteristics. Also, participants had complete oral examinations.

Results: Logistic regression analyses identified self-reported items contributing to two sets of models predicting moderate or severe periodontal disease (MODSEV) and severe periodontal disease (SEV). Age, gender, race/ethnicity, smoking, and periodontal health-related self-report items constituted predictive models with maximum sensitivity and specificity of $71 \%$ and $83 \%$, respectively, with area under the receiver operating characteristic curve (AUC) of 0.85 (as a measure of accuracy) for MODSEV. For SEV, predictive models' maximum sensitivity and specificity were $92 \%$ and $53 \%$, respectively, with a maximum AUC of 0.92 .

Conclusion: These analyses suggest that self-report may be valid for surveillance of periodontal disease burden and trends in the American population, in lieu of more costly clinical periodontal examinations. J Periodontol 2007;78:1407-1420.

\section{KEY WORDS}

Epidemiology; interviews; periodontal diseases; population; prevalence; surveillance.

\footnotetext{
* Department of Cariology, Restorative Sciences, and Endodontics, School of Dentistry University of Michigan, Ann Arbor, MI.

$\dagger$ Department of Epidemiology, School of Public Health, University of Michigan.
}

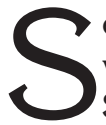
evere periodontitis is a highly prevalent chronic disease in the United States population. It is a major cause of tooth loss, resulting in diminished oral function and quality of life in adults. Also, a growing body of evidence supports important associations between periodontitis and several systemic diseases or conditions, ${ }^{1}$ including coronary heart disease, cerebral vascular disease, and peripheral arterial disease $;^{2-5}$ adverse pregnancy outcomes; ${ }^{6,7}$ glycemic control in diabetes; $;, 9$ and pneumonia in older adults. ${ }^{10,11}$ The importance of assessing periodontal health in the United States adult population is well recognized; it is a principal objective of Healthy People 2010. ${ }^{12}$ However, the 4-decade history of national, populationbased surveillance of periodontal diseases in the United States using clinical examinations was discontinued at the end of 2004. The major impediment to periodontal disease surveillance is the cost and other resources required to collect clinical data, which are the gold standard for determining periodontal disease prevalence. A possible alternative to clinical periodontal assessment is self-report, a method widely used to assess the prevalence of various medical conditions, as well as health-related behaviors and characteristics in a population.

Self-report of various medical conditions has been used for several years as a basis for monitoring health status and trends over time in the United States population. For example, the Centers 
for Disease Control and Prevention (CDC) has conducted telephone interviews regarding various health conditions, upon which important policy decisions have been made. One major example is the Behavioral Risk Factor Surveillance System (BRFSS), the world's largest telephone survey, which tracks health risks in the United States; data from the BRFSS have been used to attempt to improve the health of the American people. ${ }^{13}$

Nelson et al. ${ }^{14}$ extensively reviewed studies reporting on the reliability and validity of self-report measures from the BRFSS, including three health conditions: hypertension, diabetes, and hypercholesterolemia. They concluded that the validity for self-report of these three conditions was moderate, according to their classification of validity based on values of sensitivity and specificity, namely, high ( $\geq 80 \%)$, moderate $(60 \%$ to $79 \%)$, and low $(<60 \%)$.

The validity of self-report regarding the presence of periodontal diseases has been reported in only a few studies, as reviewed by Blicher et al. ${ }^{15}$ and Dietrich et al. ${ }^{16}$ Self-report methodology has not been used heretofore for surveillance of periodontal diseases in populations.

The goal of this study was to conduct secondary data analyses to determine the feasibility of using self-report to predict periodontal disease status. We analyzed the associations between the responses to self-reported, face-to-face interview questions related to periodontal disease status and clinical periodontal examination results. We sought to identify a set of selfreport items that could serve as proxies for clinical periodontal examinations in accurately assessing the periodontal disease status and, thereby, serve to monitor trends over time in United States populations at the national, regional, state, and local levels.

\section{MATERIALS AND METHODS}

\section{Ethical Considerations}

This study was a cross-sectional, population-based epidemiological survey, which was approved by the University of Michigan's Institutional Review Board for human research. The subjects provided informed consent prior to enrollment in the study.

\section{Study Population}

The study population was a disproportionate probability sample of adults $\geq 18$ years of age living in housing units (e.g., apartments, single-family homes, or mobile homes) in the Detroit tri-county area. Participants were selected using a stratified, clustered, area probability sampling technique based on census tracts. To strengthen analyses aimed at comparing African Americans to whites and to separate the independent effect of socioeconomic status from race, the sampling design was disproportionate and oversampled African Americans, with further oversampling of African Americans living in higher income census tracts. The ultimate sampling unit was one randomly selected adult from each selected housing unit. The sampling design has been described in detail elsewhere. ${ }^{17-19}$

\section{Interview}

Thirty-one professional interviewers from the Survey Research Center of the University of Michigan Institute for Social Research conducted in-home face-to-face interviews lasting about 65 minutes during the period from May through September 1994. Interviewers made unlimited visits to each housing unit at varying times to maximize the chance of completing the interview.

The interviewers were trained in general interviewing procedures and in the use of this study-specific questionnaire by field tests. Questions were asked verbatim, with standardized probes as needed. The wording of the questions in the survey questionnaire was guided by past research and theory and by concerns and issues expressed and terminology used in eight focus groups conducted with participants similar to the subsequent participants of the study. The questionnaire was refined based on feedback from three rounds of pilot interviews and comments from consultants. Selection of items for the interview was based on a conceptual framework that views individual characteristics, provider factors (or dental care system factors), and societal factors (or external environmental factors) as influential on oral health status. The framework also incorporates, as an outcome downstream to oral status, the impact of oral health status on the individual's quality of life. The analyses for this project focused on the individual characteristic components of this conceptual framework, including the reported impact on quality of life, to predict periodontal status. The interview yielded information about individual characteristics on demographic factors (e.g., race/ethnicity, age, gender, marital status, and education), enabling factors (e.g., income, employment status, dental insurance coverage, problems with payment for dental care, and difficulty with transportation to the dental office), psychosocial factors (e.g., perceptions of oral health and general health and of impact of getting gum disease and the respondents' attitudes toward their dental self-care and professional care), oral health-related behavioral factors (e.g., brushing and flossing frequency and adequacy; use of rubber tip, toothpicks, and mouthrinse; and dental visits), and other oral health-related risk and behavioral factors (e.g., smoking status, diabetes status, and number of teeth lost). Subjects did not receive any remuneration for completion of the interview. 
At the conclusion of the interview, participants were asked to participate in the second phase of the study, namely an hour-long in-home dental examination followed by an additional interview, lasting $\sim 15$ minutes, to assess the effect of oral health status on the quality of life by using the 49-item Oral Health Impact Profile (OHIP) questionnaire. ${ }^{20}$ OHIP captures seven dimensions that represent a theoretical hierarchy of the social impact of oral disorders in Locker's ${ }^{21}$ model of oral health. These dimensions are functional limitation, physical pain, psychologic discomfort, physical disability, psychologic disability, social disability, and handicap. Items in OHIP included general questions about the mouth and the health of the mouth, concerns for the mouth, the subject's well-being and feelings, contact with other people, general health and life, and dentures.

\section{Oral Examination}

Prior to conducting the clinical examination in the field, four dentist examiners from the University of Michigan School of Dentistry were trained and calibrated in the examination protocol by applying the study-specific criteria on 12 consenting participants who had no contraindications for periodontal examinations. Kappa statistics for coronal caries ranged from 0.88 to 0.97 ; kappa statistics for loss of periodontal attachment $( \pm 1 \mathrm{~mm})$ ranged from 0.61 to 0.83 on lingual sites and from 0.73 to 0.86 on buccal sites.

Dentist examiners conducted in-home dental examinations during the period from June through December 1994, on any day and at any time during the week. Written informed consent was obtained from all participants, and a brief medical history interview was conducted prior to performing the examinations. Subjects received $\$ 20$ for their participation in the oral examination. Dental examinations were conducted using available seating and portable headlamps.

Of the 787 participants completing the initial faceto-face interviews, 577 (73\%) completed subsequent in-home dental examinations and an additional interview. For 455 of the latter, the oral examinations included periodontal examinations; subjects excluded were edentulous, pregnant, required antibiotic prophylaxis, or had other medical contraindications for receiving periodontal examinations. The National Institute of Dental Research (NIDR) 1985-86 Adult Survey protocol ${ }^{22}$ was followed, modified to include all teeth and two additional periodontal sites on each tooth, for a total of four sites per tooth (mesio-buccal, mid-buccal, mesio-lingual and disto-lingual). The full examination protocol has been described in detail elsewhere. ${ }^{18,19}$ The periodontal examination included assessment of all teeth for gingival bleeding, presence of supra- or subgingival calculus, and measurement of probing depth (PD) and clinical attachment level on four sites of all teeth. PD was recorded as the distance, measured in millimeters, from the free gingival margin to the base of the sulcus or pocket. The distance from the free gingival margin to the cemento-enamel junction was also measured. The difference between these two measurements was considered clinical attachment loss (CAL).

\section{Periodontal Case Definitions}

Analyses for this report include the 455 participants who were dentate and completed the initial interview, the periodontal examination, and the additional interview during the dental examination visit, including the OHIP items. The following secondary analyses used the case definitions for the three levels of clinical periodontitis agreed upon in the CDC/American Academy of Periodontology (AAP) working group. ${ }^{1,23}$ To be classified as having severe periodontitis (SEV) required at least two interproximal sites on two different teeth with CAL $\geq 6 \mathrm{~mm}$ and at least one interproximal site with PD $\geq 5 \mathrm{~mm}$. Moderate periodontitis (MOD) required at least two interproximal sites with $C A L \geq 4$ $\mathrm{mm}$ on two different teeth or at least two interproximal sites with $P D \geq 5 \mathrm{~mm}$ on two different teeth. The classification of no/mild periodontitis (NO) was assigned to cases that did not qualify as having severe or moderate periodontitis. The three classifications were mutually exclusive, such that a subject could be categorized into one class/disease level only. To reduce potential bias associated with including buccal gingival recession not due to periodontitis, we excluded the mid-buccal measurements from our analyses. Hence, the case definitions in this study used three sites: mesio-buccal, mesio-lingual, and disto-lingual.

\section{Self-Report Item Selection}

To identify all self-report items having a relationship to periodontal disease, we reviewed the face-to-face in-home interview and the additional questions posed at the time of the in-home oral examination, including the OHIP questionnaire. Criteria for selecting the selfreport items included having a recognized association with periodontal disease as a risk indicator or risk factor or having face validity as being associated with periodontal disease if not previously reported in the literature. This process resulted in 86 items from the interviews, including 46 OHIP items, which were selected for an initial pool of possible candidate variables for inclusion as predictor variables in the logistic regression modeling. The broad categories of predictor variables identified included demographic, enabling/ access, behavioral, attitudinal, self-rated oral and general health, and specific questions about periodontal health and tooth loss.

In addition to selecting questions in their original form, some new variables were created by combining 
two original items into one derived variable. Also, new variables were created by recategorizing original variables to specify variables as similar as possible to items currently included in the BRFSS. ${ }^{13}$ The BRFSS-like items used in the analyses included race, gender, age, education, employment status, family income, cigarette smoking, number of dental check-ups, tooth loss, diabetes, and self-rated general health.

\section{Logistic Regression Model Construction}

After creating the pool of 86 variables to test as predictors of periodontal disease, we used logistic regression with forward, backward, stepwise, and score selection algorithms in a statistical software program ${ }^{\ddagger}$ to identify potential predictors of both specifications of the periodontal disease outcome. Variables identified as having a $P$ value $\leq 0.1$ by any of the selection algorithms were included in two separate final pools of predictors used for modeling the best set of predictors for each outcome, no or mild versus moderate or severe periodontitis (NO_MODSEV) and no, mild, or moderate versus severe periodontitis (NOMOD_SEV). These steps resulted in a pool of 19 predictor variables for NO_MODSEV and 15 predictor variables for NOMOD_SEV.

Next, we used the selection algorithms in two separate steps for the demographic variables only and the dental variables only to identify the best subsets of these demographic and dental variables to force into candidate models. We then conducted four sets of logistic regression analyses for each of the two periodontal disease outcomes. The first analysis forced the demographic variables into a set of logistic regression models using the forward selection algorithm to determine the best models with the forced demographic variables and one to six additional dental predictor variables from the remaining variables in the pool of 19 variables for NO_MODSEV and 15 variables for NOMOD_SEV. The second analysis forced the dental variables into a set of logistic regression models using the forward selection algorithm to determine the best models with the forced dental variables and one to six additional demographic variables from the respective pools of previously identified variables for both outcome variables. The third analysis used the score selection algorithm to identify the four best models with four to eight predictor variables without any variables forced. The fourth analysis used the stepwise selection routine to identify the single models with the best set of predictor variables for each of the two outcomes; this model also allowed verification of the best model identified from the score selection analyses.

Next, we selected three best models for each of the outcomes, one model each from the candidate models estimated from the forced demographic pre- dictors, forced dental predictors, and non-forced selection methods. The criteria used for selecting the best models included the C-statistic (area under the receiver operation characteristic curve), likelihood ratio $\chi^{2}$ statistic, $R^{2}$ statistic, and sensitivity and specificity. We estimated sensitivity and specificity at the prevalence predicted by the logistic regression models that conformed to the observed prevalence of disease based on clinical findings. Finally, in selecting the best models we also considered parsimony.

As a final evaluation after selecting the three best models for each of the two outcomes, we conducted a test to assess whether any of the original pool of variables with responses available from the dentate members of the entire group of 787 participants completing the initial in-home interview were significant in predicting the probability of having the periodontal examination. By including participants who had periodontal examinations as well as those who did not, this assessment provided a way to determine whether there were any characteristics among those who did not have periodontal examinations that might have been influential in not having a periodontal examination. For each of the selected variables, we performed ordinary logistic regression to test whether each of the variables, separately, was associated significantly $(P$ $\leq 0.05$ ) with the probability of having a periodontal examination. This was done to determine whether there were any significant differences in the distributions of variables between participants with and without periodontal examinations. Next, we tested the variables that were significantly associated with having a periodontal examination in the final candidate models for each of the two periodontal disease outcomes by performing stepwise logistic regression. This regression step allowed us to determine whether any of those variables had a significant effect in the final candidate models. None of the tested variables (that were not already in the candidate models) were statistically significant, so we were able to retain the final candidate models as originally constructed.

\section{RESULTS}

Four hundred fifty-five dentate subjects who completed the in-home periodontal examination were included in the analyses. Their ages ranged from 18 to 93 years. The average age was 36.4 years (median, 36 years; range: 18 to 81 years) for subjects with no/mild periodontitis, 49.2 years (median, 46 years; range: 19 to 85 years) for subjects with moderate periodontitis, and 56.3 years (median, 57 years; range: 29 to 93 years) for subjects with severe periodontitis.

† SAS systems for Windows, version 9.1, SAS Institute, Cary, NC. 
Table 1 displays the prevalence of the three levels of periodontal disease in subgroups of subjects with various characteristics. For instance, $88.6 \%$ of the 18 - to 29 -year-olds, but only $23.1 \%$ of those $\geq 65$ years of age, had no/mild disease, whereas $<2 \%$ of subjects younger than 40 years of age versus $>30 \%$ of those older than 55 years of age had severe periodontitis. Males had more severe disease as did non-whites. Poorer self-rated general and oral health was associated with more severe periodontitis. More than $80 \%$ of those without tooth loss had no/mild disease compared to $<40 \%$ of those missing more than five teeth. Of the former, $<4 \%$ had severe disease, whereas more than one-third of the latter did. Almost half of subjects who reported loosening of teeth had severe periodontitis versus $<10 \%$ of those who did not report loose teeth ever. Seventy percent to $75 \%$ of those who rarely noticed a tooth not looking right had no/mild disease, whereas $\sim 15 \%$ to $20 \%$ of those noticing such teeth sometimes to fairly often had severe periodontitis. It should be mentioned that in some cases the subgroups shown in Table 1 are for illustrative/descriptive purposes only, and other specifications of selected variables were used in the analyses. For example, continuous variables for age and household income were used in the analyses and categorical specifications are shown in the table. Also, the category of "none/ kindergarten only" for education is not shown in any table because of a lack of observations in that category.

Tables 2 and 3 show the statistical measures of validity for the best candidate models from the three different model construction approaches. These tables also show the predictor variables for each of the two specifications of the periodontal disease outcome, NO_MODSEV (Table 2) and NOMOD_SEV (Table $3)$. The tables also contain the measures of validity and variables used in the demographic variableand dental variable-only models, respectively. The three different model construction approaches that include both demographic and dental variables for each outcome are very similar in the values for the statistical measures of validity. The models using both demographic and dental variables perform better than the models using only demographic or only dental variables.

Tables 4 and 5 show the distribution of subjects' responses to each of the predictor variables in the final candidate logistic regression models for each of the periodontal disease outcomes specified as no or mild periodontitis versus moderate or severe periodontitis (Table 4) and no or moderate periodontitis versus severe periodontitis (Table 5). In Table 4, the distribution of responses for the predictor variables, age, painful gums, race, "think have gum disease," and noticed a "tooth not looking right," follow the anticipated magnitude and direction with respect to the categories of the predictor variables that have greater proportions with moderate or severe periodontitis. The expected pattern also is observed for gender and smoking, although the differences in proportions with moderate or severe periodontitis between males and females and between smokers and non-smokers are not as great as might be anticipated.

Table 5 shows a general tendency for subjects with severe periodontitis to have greater proportions in the expected categories of the predictor variables for age, gender, mouthwash use, loosened teeth, thinking they have gum disease, and noticing a tooth not looking right. There was a tendency for more frequent toothpick use in those with severe periodontitis; however, the pattern could not be discerned as clearly.

The parameter estimates for models $1 \mathrm{~A}$ and $2 \mathrm{~A}$, in which no variables were forced, appear in Table 6 to provide additional insight into how the individual predictor variables were associated with the two clinical periodontal disease outcomes in their respective models. Each model has seven variables; four variables are common to both models. Only 10 different variables qualified to be included in these two models, of which four were demographic or behavioral (smoking) and six were dental.

Table 7 provides detailed information about the content of each question and the response values for each of the predictor variables used in the candidate models. Two OHIP variables made it into these models: painful gums and tooth not looking right.

\section{DISCUSSION}

The results obtained in these analyses provide additional evidence to support the feasibility of using selfreport to assess periodontal disease prevalence in population-based studies. The models identified candidate sets of questions that could predict periodontal disease prevalence with reasonable validity. Our results for the validity of using periodontal self-report items were similar to those reported by Nelson et al. ${ }^{14}$ in their extensive review of assessments of the validity of self-report measures from the BRFSS that included three health conditions: hypertension, diabetes, and hypercholesterolemia.

Using the validity classification based on sensitivity and specificity $(<60 \%=$ low; $60 \%$ to $79 \%=$ moderate; and $\geq 80 \%=$ high), Nelson et al. ${ }^{14}$ reviewed 12 hypertension studies and found moderate sensitivity (averaging between $70 \%$ and $80 \%$ ) and high specificity (ranging from $80 \%$ to $90 \%$ ). For diabetes, they reported on nine studies with information regarding the validity of self-reported data, finding sensitivity $>85 \%$ and specificity $>95 \%$ in many, but not all, of the studies, and they concluded that the validity was moderate. Finally, for hypercholesterolemia, they compared self-reports with physiologic measures 
Table I.

Distribution of Subjects With Selected Demographic, Oral, Attitudinal, and Behavioral Characteristics by Periodontitis Category $(\mathrm{N}=455)$

\begin{tabular}{|c|c|c|c|c|c|c|c|}
\hline \multirow[b]{3}{*}{ Characteristic } & \multirow[b]{3}{*}{$N$} & \multicolumn{6}{|c|}{ Periodontitis Category } \\
\hline & & \multicolumn{2}{|c|}{ No/Mild } & \multicolumn{2}{|c|}{ Moderate } & \multicolumn{2}{|c|}{ Severe } \\
\hline & & $n$ & $\%$ & $n$ & $\%$ & $n$ & $\%$ \\
\hline All & 455 & 289 & 63.5 & 110 & 24.2 & 56 & 12.3 \\
\hline $\begin{array}{l}\text { Age (years) } \\
18 \text { to } 29 \\
30 \text { to } 39 \\
40 \text { to } 54 \\
55 \text { to } 64 \\
\geq 65\end{array}$ & $\begin{array}{r}455 \\
105 \\
128 \\
129 \\
41 \\
52\end{array}$ & $\begin{array}{r}93 \\
100 \\
72 \\
12 \\
12\end{array}$ & $\begin{array}{l}88.6 \\
78.1 \\
55.8 \\
29.3 \\
23.1\end{array}$ & $\begin{array}{l}10 \\
26 \\
36 \\
14 \\
24\end{array}$ & $\begin{array}{r}9.5 \\
20.3 \\
27.9 \\
34.1 \\
46.1\end{array}$ & $\begin{array}{r}2 \\
2 \\
21 \\
15 \\
16\end{array}$ & $\begin{array}{r}1.9 \\
1.6 \\
16.3 \\
36.6 \\
30.8\end{array}$ \\
\hline $\begin{array}{l}\text { Gender } \\
\text { Male } \\
\text { Female }\end{array}$ & $\begin{array}{l}455 \\
194 \\
261\end{array}$ & $\begin{array}{l}117 \\
172\end{array}$ & $\begin{array}{l}60.3 \\
65.9\end{array}$ & $\begin{array}{l}43 \\
67\end{array}$ & $\begin{array}{l}22.2 \\
25.7\end{array}$ & $\begin{array}{l}34 \\
22\end{array}$ & $\begin{array}{r}17.5 \\
8.4\end{array}$ \\
\hline $\begin{array}{l}\text { Race } \\
\text { White } \\
\text { Non-white }\end{array}$ & $\begin{array}{l}455 \\
210 \\
245\end{array}$ & $\begin{array}{l}146 \\
143\end{array}$ & $\begin{array}{l}69.5 \\
58.4\end{array}$ & $\begin{array}{l}42 \\
68\end{array}$ & $\begin{array}{l}20.0 \\
27.7\end{array}$ & $\begin{array}{l}22 \\
34\end{array}$ & $\begin{array}{l}10.5 \\
13.9\end{array}$ \\
\hline $\begin{array}{l}\text { Hispanic origin } \\
\text { No } \\
\text { Yes }\end{array}$ & $\begin{array}{r}453 \\
437 \\
16\end{array}$ & $\begin{array}{r}276 \\
13\end{array}$ & $\begin{array}{l}63.2 \\
81.3\end{array}$ & $\begin{array}{r}106 \\
3\end{array}$ & $\begin{array}{l}24.2 \\
18.7\end{array}$ & $\begin{array}{r}55 \\
0\end{array}$ & $\begin{array}{c}12.6 \\
0\end{array}$ \\
\hline $\begin{array}{l}\text { Education } \\
\text { Grades I to } 8 \\
\text { Grades } 9 \text { to II } \\
\text { Grade I } 2 \\
\text { College I to } 3 \text { years } \\
\text { College } \geq 4 \text { years }\end{array}$ & $\begin{array}{r}454 \\
10 \\
53 \\
148 \\
135 \\
108\end{array}$ & $\begin{array}{r}3 \\
25 \\
85 \\
95 \\
81\end{array}$ & $\begin{array}{l}30.0 \\
47.2 \\
57.4 \\
70.4 \\
75.0\end{array}$ & $\begin{array}{r}3 \\
16 \\
43 \\
29 \\
18\end{array}$ & $\begin{array}{l}30.0 \\
30.2 \\
29.1 \\
21.5 \\
16.7\end{array}$ & $\begin{array}{r}4 \\
12 \\
20 \\
11 \\
9\end{array}$ & $\begin{array}{r}40.0 \\
22.6 \\
13.5 \\
8.1 \\
8.3\end{array}$ \\
\hline $\begin{array}{l}\text { Income } \\
<\$ 20,000 \\
\$ 20,000 \text { to } \$ 39,999 \\
\$ 40,000 \text { to } \$ 69,999 \\
\geq \$ 70,000\end{array}$ & $\begin{array}{r}455 \\
132 \\
109 \\
131 \\
83\end{array}$ & $\begin{array}{l}74 \\
65 \\
87 \\
63\end{array}$ & $\begin{array}{l}56.1 \\
59.6 \\
66.4 \\
75.9\end{array}$ & $\begin{array}{l}43 \\
24 \\
29 \\
14\end{array}$ & $\begin{array}{l}32.6 \\
22.0 \\
22.1 \\
16.9\end{array}$ & $\begin{array}{r}15 \\
20 \\
15 \\
6\end{array}$ & $\begin{array}{r}11.3 \\
18.4 \\
11.5 \\
7.2\end{array}$ \\
\hline $\begin{array}{l}\text { Working for pay } \\
\text { No } \\
\text { Yes }\end{array}$ & $\begin{array}{l}455 \\
146 \\
309\end{array}$ & $\begin{array}{r}74 \\
215\end{array}$ & $\begin{array}{l}50.7 \\
69.6\end{array}$ & $\begin{array}{l}47 \\
63\end{array}$ & $\begin{array}{l}32.2 \\
20.4\end{array}$ & $\begin{array}{l}25 \\
31\end{array}$ & $\begin{array}{l}17.1 \\
10.0\end{array}$ \\
\hline $\begin{array}{l}\text { Smoking } \\
\text { No } \\
\text { Yes }\end{array}$ & $\begin{array}{l}455 \\
314 \\
141\end{array}$ & $\begin{array}{r}204 \\
85\end{array}$ & $\begin{array}{l}65.0 \\
60.3\end{array}$ & $\begin{array}{l}72 \\
38\end{array}$ & $\begin{array}{l}22.9 \\
26.9\end{array}$ & $\begin{array}{l}38 \\
18\end{array}$ & $\begin{array}{l}12.1 \\
12.8\end{array}$ \\
\hline $\begin{array}{l}\text { Diabetes } \\
\text { No } \\
\text { Yes }\end{array}$ & $\begin{array}{r}455 \\
434 \\
21\end{array}$ & $\begin{array}{r}282 \\
7\end{array}$ & $\begin{array}{l}65.0 \\
33.3\end{array}$ & $\begin{array}{r}103 \\
7\end{array}$ & $\begin{array}{l}23.7 \\
33.3\end{array}$ & $\begin{array}{r}49 \\
7\end{array}$ & $\begin{array}{l}11.3 \\
33.4\end{array}$ \\
\hline $\begin{array}{l}\text { Self-rated general health } \\
\text { Excellent } \\
\text { Very good } \\
\text { Good } \\
\text { Fair } \\
\text { Poor }\end{array}$ & $\begin{array}{r}449 \\
107 \\
188 \\
114 \\
35 \\
5\end{array}$ & $\begin{array}{r}78 \\
121 \\
69 \\
16 \\
1\end{array}$ & $\begin{array}{l}72.9 \\
64.4 \\
60.5 \\
45.7 \\
20.0\end{array}$ & $\begin{array}{r}21 \\
44 \\
31 \\
11 \\
2\end{array}$ & $\begin{array}{l}19.6 \\
23.4 \\
27.2 \\
31.4 \\
40.0\end{array}$ & $\begin{array}{r}8 \\
23 \\
14 \\
8 \\
2\end{array}$ & $\begin{array}{r}7.5 \\
12.2 \\
12.3 \\
22.9 \\
40.0\end{array}$ \\
\hline
\end{tabular}


Table I. (continued)

Distribution of Subjects With Selected Demographic, Oral, Attitudinal, and Behavioral Characteristics by Periodontitis Category ( $N=455)$

\begin{tabular}{|c|c|c|c|c|c|c|c|}
\hline \multirow[b]{3}{*}{ Characteristic } & \multirow[b]{3}{*}{$\mathrm{N}$} & \multicolumn{6}{|c|}{ Periodontitis Category } \\
\hline & & \multicolumn{2}{|c|}{ No/Mild } & \multicolumn{2}{|c|}{ Moderate } & \multicolumn{2}{|c|}{ Severe } \\
\hline & & $n$ & $\%$ & $\mathrm{n}$ & $\%$ & $n$ & $\%$ \\
\hline Self-rated oral health & 455 & & & & & & \\
\hline Excellent & 84 & 64 & 76.2 & 16 & 19.0 & 4 & 4.8 \\
\hline Good & 209 & 139 & 66.5 & 46 & 22.0 & 24 & 11.5 \\
\hline Fair & 131 & 78 & 59.6 & 35 & 26.7 & 18 & 13.7 \\
\hline Poor & 31 & 8 & 25.8 & 13 & 41.9 & 10 & 32.3 \\
\hline Tooth loss & 450 & & & & & & \\
\hline None & 183 & $15 \mid$ & 82.5 & 25 & 13.7 & 7 & 3.8 \\
\hline I to 5 teeth & 157 & 94 & 59.9 & 51 & 32.5 & 12 & 7.6 \\
\hline 6 to 31 teeth & 110 & 41 & 37.3 & 32 & 29.1 & 37 & 33.6 \\
\hline Teeth loosened & 455 & & & & & & \\
\hline No & 407 & 275 & 67.6 & 99 & 24.3 & 33 & 8.1 \\
\hline Yes & 48 & 14 & 29.2 & 11 & 22.9 & 23 & 47.9 \\
\hline Hurting teeth & 455 & & & & & & \\
\hline No & 346 & 218 & 63.0 & 85 & 24.6 & 43 & 12.4 \\
\hline Yes & 109 & 71 & 65.1 & 25 & 23.0 & 13 & 11.9 \\
\hline Tooth not looking right & 455 & & & & & & \\
\hline Never & 219 & 153 & 69.9 & 45 & 20.5 & 21 & 9.6 \\
\hline Hardly ever & 49 & 37 & 75.5 & 11 & 22.5 & I & 2.0 \\
\hline Sometimes & 85 & 51 & 60.0 & 21 & 24.7 & 13 & 15.3 \\
\hline Fairly often & 31 & 15 & 48.4 & 10 & 32.3 & 6 & 19.3 \\
\hline Very often & 71 & 33 & 46.5 & 23 & 32.4 & 15 & 21.1 \\
\hline Think have gum disease & 441 & & & & & & \\
\hline No & 389 & 264 & 67.9 & 87 & 22.4 & 38 & 9.8 \\
\hline Yes & 52 & 19 & 36.5 & 17 & 32.7 & 16 & 30.8 \\
\hline Likely to get gum disease & 452 & & & & & & \\
\hline Very likely & 33 & 16 & 48.5 & 8 & 24.2 & 9 & 27.3 \\
\hline Somewhat likely & 76 & 37 & 48.7 & 24 & 31.6 & 15 & 19.7 \\
\hline 50-50 chance & 106 & 57 & 53.8 & 30 & 28.3 & 19 & 17.9 \\
\hline Somewhat unlikely & 131 & 102 & 77.8 & 20 & 15.3 & 9 & 6.9 \\
\hline Very unlikely & 106 & 75 & 70.8 & 28 & 26.4 & 3 & 2.8 \\
\hline Gums bled past week & 455 & & & & & & \\
\hline No & 377 & 241 & 63.9 & 92 & 24.4 & 44 & 11.7 \\
\hline Yes & 78 & 48 & 61.5 & 18 & 23.1 & 12 & 15.4 \\
\hline Painful gums & 455 & & & & & & \\
\hline Never & 296 & 201 & 67.9 & 63 & 21.3 & 32 & 10.8 \\
\hline Hardly ever & 59 & 37 & 62.7 & 15 & 25.4 & 7 & 11.9 \\
\hline Sometimes & 73 & 35 & 47.9 & 23 & 31.5 & 15 & 20.6 \\
\hline Fairly often & 17 & 12 & 70.6 & 5 & 29.4 & 0 & 0.0 \\
\hline Very often & 10 & 4 & 40.0 & 4 & 40.0 & 2 & 20.0 \\
\hline Unable to brush teeth & 455 & & & & & & \\
\hline Never & 347 & 231 & 66.6 & 78 & 22.5 & 38 & 10.9 \\
\hline Hardly ever & 38 & 22 & 57.9 & 8 & 21.1 & 8 & 21.0 \\
\hline Sometimes & 47 & 23 & 48.9 & 16 & 34.1 & 8 & 17.0 \\
\hline Fairly often & 11 & 8 & 72.7 & 2 & 18.2 & I & 9.1 \\
\hline Very often & 12 & 5 & 41.7 & 6 & 50.0 & I & 8.3 \\
\hline
\end{tabular}


Table I. (continued)

Distribution of Subjects With Selected Demographic, Oral, Attitudinal, and Behavioral Characteristics by Periodontitis Category $(\mathrm{N}=455)$

\begin{tabular}{|c|c|c|c|c|c|c|c|}
\hline \multirow[b]{3}{*}{ Characteristic } & \multirow[b]{3}{*}{$\mathrm{N}$} & \multicolumn{6}{|c|}{ Periodontitis Category } \\
\hline & & \multicolumn{2}{|c|}{ No/Mild } & \multicolumn{2}{|c|}{ Moderate } & \multicolumn{2}{|c|}{ Severe } \\
\hline & & $n$ & $\%$ & $\mathrm{n}$ & $\%$ & $\mathrm{n}$ & $\%$ \\
\hline Mouthwash use & 455 & & & & & & \\
\hline >2 times/day & 10 & 7 & 70.0 & 2 & 20.0 & I & 10.0 \\
\hline 2 times/day & 60 & 33 & 55.0 & 15 & 25.0 & 12 & 20.0 \\
\hline About I time/day & 128 & 71 & 55.5 & 36 & 28.1 & 21 & 16.4 \\
\hline About once every 2 days & 36 & 21 & 58.3 & 9 & 25.0 & 6 & 16.7 \\
\hline I to 2 times/week & 38 & 26 & 68.4 & 9 & 23.7 & 3 & 7.9 \\
\hline$<1$ time/week & 79 & 60 & 75.9 & 13 & 16.5 & 6 & 7.6 \\
\hline Never & 104 & 71 & 68.3 & 26 & 25.0 & 7 & 6.7 \\
\hline Toothpick use past year & 453 & & & & & & \\
\hline$>2$ times/day & 4 & I & 25.0 & 1 & 25.0 & 2 & 50.0 \\
\hline 2 times/day & 0 & 0 & 0.0 & 0 & 0.0 & 0 & 0.0 \\
\hline About I time/day & 8 & 3 & 37.5 & 2 & 25.0 & 3 & 37.5 \\
\hline About once every 2 days & 2 & 0 & 0.0 & 2 & 100 & 0 & 0.0 \\
\hline I to 2 times/week & 7 & 6 & 85.7 & 0 & 0.0 & I & 14.3 \\
\hline$<1$ time/week & 34 & 17 & 50.0 & 6 & 17.7 & 11 & 32.3 \\
\hline Never & 398 & 261 & 65.6 & 98 & 24.6 & 39 & 9.8 \\
\hline Dental checkups last 5 years & 420 & & & & & & \\
\hline$>2$ times/year & 45 & 24 & 53.3 & 13 & 28.9 & 8 & 17.8 \\
\hline 2 times/year & 158 & 114 & 72.1 & 30 & 19.0 & 14 & 8.9 \\
\hline I time/year & 92 & 61 & 66.3 & 21 & 22.8 & 10 & 10.9 \\
\hline I time/2 years & 71 & 43 & 60.5 & 21 & 29.6 & 7 & 9.9 \\
\hline I time/5 years & 33 & 22 & 66.7 & 8 & 24.2 & 3 & 9.1 \\
\hline None & 21 & 12 & 57.1 & 8 & 38.1 & I & 4.8 \\
\hline Usual dental care source & 455 & & & & & & \\
\hline No & 79 & 43 & 54.4 & 22 & 27.9 & 14 & 17.7 \\
\hline Yes & 376 & 246 & 65.4 & 88 & 23.4 & 42 & 11.2 \\
\hline Dental insurance status & 453 & & & & & & \\
\hline Uninsured & 118 & 73 & 61.9 & 26 & 22.0 & 19 & 16.1 \\
\hline Medicaid only & 46 & 26 & 56.5 & 16 & 34.8 & 4 & 8.7 \\
\hline Other insurance & 289 & 189 & 65.4 & 67 & 23.2 & 33 & 11.4 \\
\hline
\end{tabular}

and medical records, identifying two studies with assessment of BRFSS data for several subgroups, with sensitivity ranging from $32 \%$ to $59 \%$ and specificity ranging from $58 \%$ to $100 \%$, again concluding that the validity was moderate.

The models we developed from our analyses are intuitively sensible and performed at least moderately well with respect to the level of predictive validity using the criteria of the C-statistic and values for sensitivity and specificity, which were included in the criteria selected by the CDC working group to evaluate the performance of models evaluated in this project. The values for sensitivity and specificity found in the candidate models estimated in our analyses fall within the ranges Nelson et al. ${ }^{14}$ reported in their analyses of the routinely used self-report items in the BRFSS. Although the individual values of sensitivity for the outcome severe periodontitis were $<60 \%$ in each of the best candidate models (Table 3 ), three of the candidate models for severe periodontitis (models 2A, 2B, and 2C) had combined sensitivity and specificity $>140$. Blicher et al. ${ }^{15}$ suggested that it is reasonable to consider a measure as having good validity when the sum of the sensitivity plus specificity values is $\geq 120$. They further argued that it is important to consider the combination of sensitivity plus specificity because in the context of validating measures for etiologic studies, surveys, or surveillance, it often is 
Table 2.

\section{Characteristics of the Best Candidate Logistic Regression Models Predicting Periodontal Disease Status: NO_MODSEV}

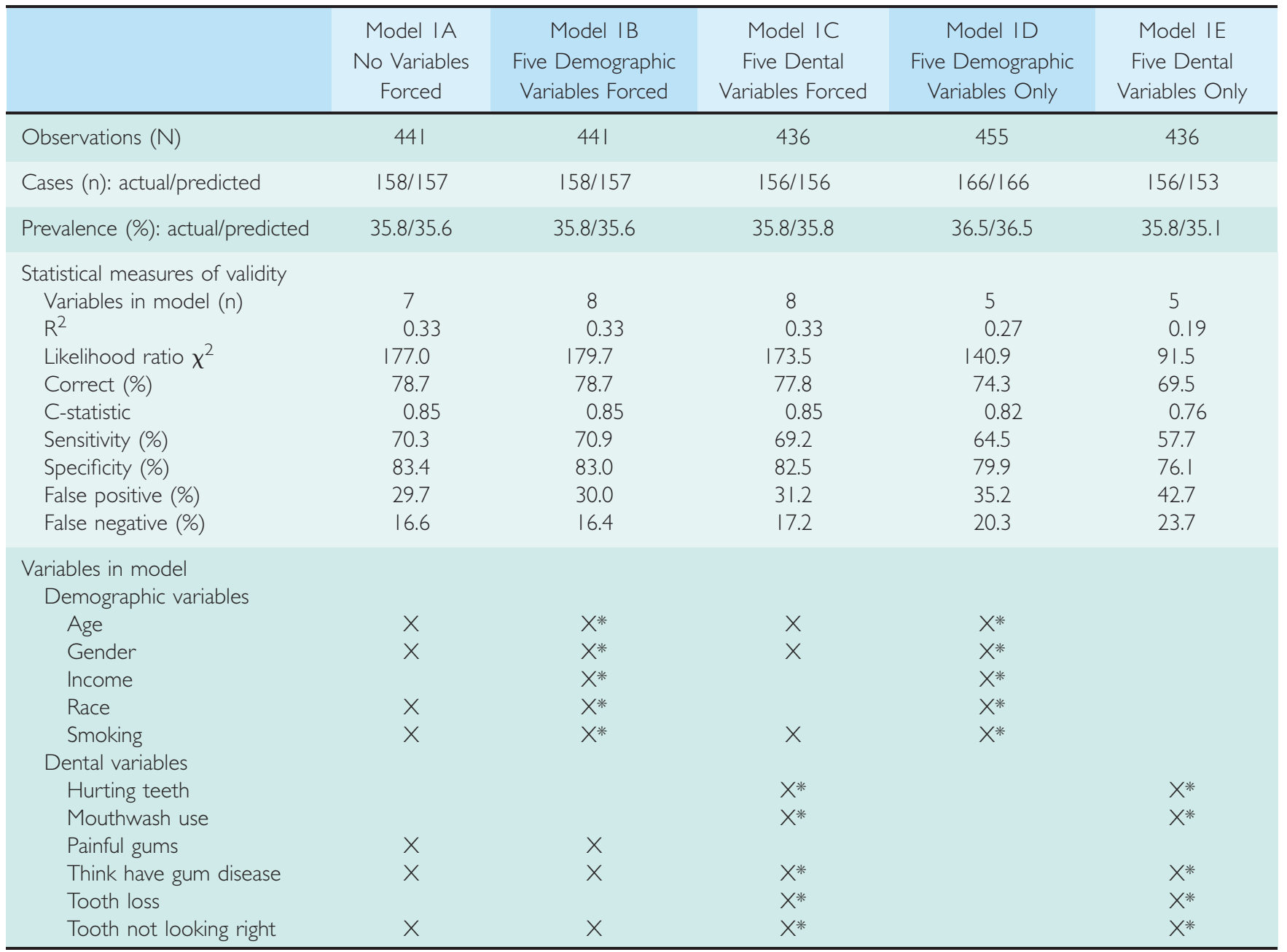

$\mathrm{X}=$ variable included in model.

* Variable forced into model.

difficult to determine the relative importance of sensitivity and specificity individually.

The values obtained for estimates of the $\mathrm{C}$-statistics reflect moderately accurate models. Although there are no established criteria for acceptable levels of model accuracy using the C-statistic, Swets $^{24}$ proposed values of the $\mathrm{C}$-statistic representing low accuracy, useful or moderate accuracy, and high accuracy to be between 0.50 and $0.70,0.70$ and 0.90 , and $\geq 0.90$, respectively. An intuitive interpretation of the $\mathrm{C}$-statistic as a measure of accuracy is to consider it representing the relationship between the proportions of true positives to false positives as determined by the logistic regression model.

The models for each outcome (i.e., NO_MODSEV and NOMOD_SEV) to identify the set of predictor variables among their three respective candidate models that included demographic and dental variables were very similar in the measures of validity, regardless of the model building approach used. Several dental variables were common to several of the models for both outcomes. Altogether, nine dental variables, four demographic variables, and one health-related behavioral variable appear in one or more of the models predicting the two periodontal disease outcomes. We estimated well-performing candidate models for NO_MODSEV using three non-forced dental variables in combination with demographic variables. Similarly, we estimated reasonably well-performing prediction models for NOMOD_SEV with four or five dental variables in combination with a subset of demographic variables. The numbers of dental variables in the models could have important implications in selecting dental items to include based on costs 
Table 3.

\section{Characteristics of the Best Candidate Logistic Regression Models Predicting Periodontal Disease Status: NOMOD_SEV}

\begin{tabular}{|c|c|c|c|c|c|}
\hline & $\begin{array}{l}\text { Model 2A } \\
\text { No Variables } \\
\text { Forced }\end{array}$ & $\begin{array}{l}\text { Model 2B } \\
\text { Three Demographic } \\
\text { Variables Forced }\end{array}$ & $\begin{array}{c}\text { Model } 2 \mathrm{C} \\
\text { Four Dental } \\
\text { Variables Forced }\end{array}$ & $\begin{array}{l}\text { Model 2D } \\
\text { Three Demographic } \\
\text { Variables Only }\end{array}$ & $\begin{array}{c}\text { Model } 2 \mathrm{E} \\
\text { Four Dental } \\
\text { Variables Only }\end{array}$ \\
\hline Observations (N) & 439 & 450 & 450 & 455 & 450 \\
\hline Cases (n): actual/predicted & $54 / 53$ & $55 / 54$ & $55 / 54$ & $56 / 54$ & $55 / 48$ \\
\hline Prevalence (\%): actual/predicted & $12.3 / 12.1$ & $12.2 / 12.0$ & $12.2 / 12.0$ & $12.3 / 11.9$ & $12.2 / 10.7$ \\
\hline $\begin{array}{l}\text { Statistical measures of validity } \\
\text { Variables in model (n) } \\
\mathrm{R}^{2} \\
\text { Likelihood ratio } \chi^{2} \\
\text { Correct (\%) } \\
\text { C-statistic } \\
\text { Sensitivity (\%) } \\
\text { Specificity (\%) } \\
\text { False positive (\%) } \\
\text { False negative (\%) }\end{array}$ & $\begin{array}{c}7 \\
0.26 \\
134.2 \\
88.2 \\
0.92 \\
50.0 \\
93.5 \\
48.1 \\
7.0\end{array}$ & $\begin{array}{c}8 \\
0.25 \\
127.9 \\
88.0 \\
0.92 \\
47.3 \\
93.7 \\
49.0 \\
7.3\end{array}$ & $\begin{array}{c}6 \\
0.23 \\
117.0 \\
88.4 \\
0.90 \\
52.7 \\
93.4 \\
47.3 \\
6.6\end{array}$ & $\begin{array}{l}3 \\
0.14 \\
66.7 \\
84.4 \\
0.84 \\
33.9 \\
91.5 \\
64.2 \\
9.2\end{array}$ & $\begin{array}{l}4 \\
0.13 \\
63.2 \\
86.9 \\
0.79 \\
47.3 \\
92.4 \\
53.6 \\
7.4\end{array}$ \\
\hline $\begin{array}{l}\text { Variables in model } \\
\text { Demographic variables }\end{array}$ & & & & & \\
\hline $\begin{array}{l}\text { Age } \\
\text { Gender } \\
\text { Race } \\
\text { Education }\end{array}$ & $\begin{array}{l}X \\
X\end{array}$ & $\begin{array}{l}X^{*} \\
X^{*} \\
X^{*}\end{array}$ & $\begin{array}{l}X \\
X\end{array}$ & $\begin{array}{l}X^{*} \\
X^{*} \\
X^{*}\end{array}$ & \\
\hline $\begin{array}{l}\text { Dental variables } \\
\text { Likely to get gum disease } \\
\text { Mouthwash use } \\
\text { Teeth loosened } \\
\text { Think have gum disease } \\
\text { Tooth not looking right } \\
\text { Toothpick use past year }\end{array}$ & $\begin{array}{l}x \\
x \\
x \\
x \\
x\end{array}$ & $\begin{array}{l}x \\
x \\
x\end{array}$ & $\begin{array}{l}X^{*} \\
X^{*} \\
X^{*}\end{array}$ & & $\begin{array}{l}X^{*} \\
X^{*} \\
X^{*}\end{array}$ \\
\hline
\end{tabular}

$\mathrm{X}=$ variable included in model.

* Variable forced into model.

of including those additional items in preexisting surveys where the demographic questions and smoking behavior often are collected already.

The set of dental questions included in the estimated models is administered easily, at least in an Englishspeaking population. One limitation of this analysis is that we were not able to obtain information on how well these items perform in non-English-speaking populations. However, the items selected from the OHIP have been validated and used extensively internationally among several non-English-speaking populations with various native languages. ${ }^{25-36}$

Another potential limitation of the study is the use of four sites, instead of six sites, per tooth to determine clinical periodontal status and the subsequent use of only three of these sites for the case definitions and analyses for this report. This examination methodol- ogy may have underestimated the prevalence of periodontal disease and may have led to misclassification of periodontal status for some of the participants. Such misclassification might have contributed to attenuation of C-statistics, sensitivities, and specificities greater than would have been the case if six sites per tooth had been assessed.

To evaluate further whether substantial selection bias was associated with the participants who had periodontal examinations, we assessed the distribution of selected characteristics using the variables in Table 1 . We made two sets of comparisons for the participants who had periodontal examinations: 1) comparing them to participants who had in-home dental examinations and additional interview visits but did not have periodontal examinations ( $n=122)$, and 2) comparing them to participants who did not have the in-home 
Table 4.

Distribution of Subjects' Responses to the Seven Predictor Variables in the Selected* Logistic Regression Model Predicting the Periodontal Disease Outcome NO_MODSEV

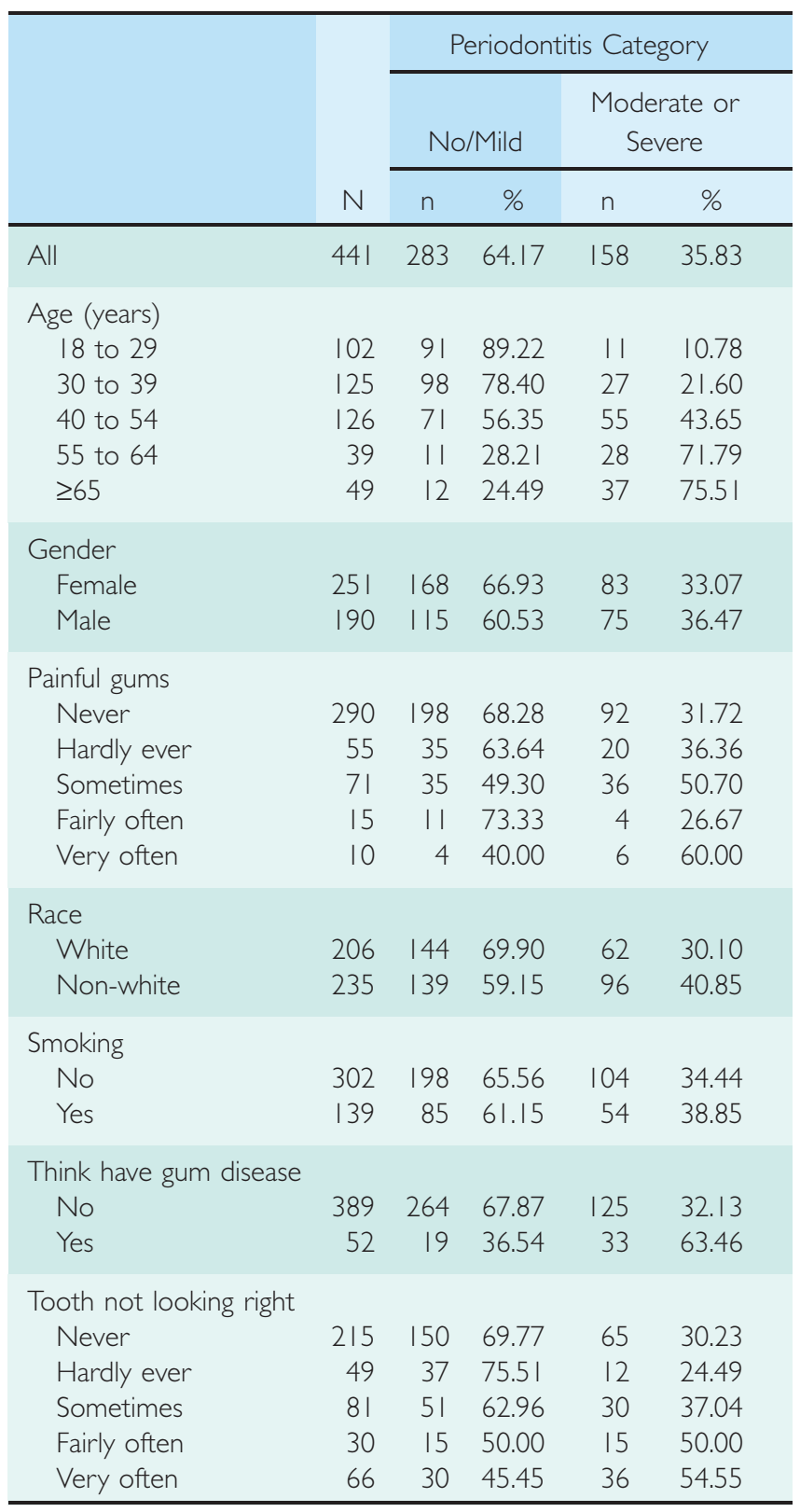

* Model 1A displayed in Table 2.

dental examination and additional interview ( $\mathrm{n}=$ 210). For the comparisons between those with periodontal examination and those with in-home examinations but no periodontal examinations, we found 50 participants who were edentulous. In comparing the distribution of the characteristics for the 25 variables in Table 1 for dentate participants with in-home
Table 5.

Distribution of Subjects' Responses to the Seven Predictor Variables in the Selected* Logistic Regression Model Predicting the Periodontal Disease

\section{Outcome NOMOD_SEV}

\begin{tabular}{|c|c|c|c|c|c|}
\hline & \multirow[b]{3}{*}{$\mathrm{N}$} & \multicolumn{4}{|c|}{ Periodontitis Category } \\
\hline & & \multicolumn{2}{|c|}{$\begin{array}{l}\text { No/Mild or } \\
\text { Moderate }\end{array}$} & \multicolumn{2}{|c|}{ Severe } \\
\hline & & $n$ & $\%$ & $n$ & $\%$ \\
\hline All & 439 & 385 & 87.70 & 54 & 12.30 \\
\hline $\begin{array}{l}\text { Age (years) } \\
18 \text { to } 29 \\
30 \text { to } 39 \\
40 \text { to } 54 \\
55 \text { to } 64 \\
\geq 65\end{array}$ & $\begin{array}{r}102 \\
125 \\
125 \\
38 \\
49\end{array}$ & $\begin{array}{r}100 \\
123 \\
104 \\
23 \\
35\end{array}$ & $\begin{array}{l}98.04 \\
98.40 \\
83.20 \\
60.53 \\
71.43\end{array}$ & $\begin{array}{r}2 \\
2 \\
21 \\
15 \\
14\end{array}$ & $\begin{array}{r}1.96 \\
1.60 \\
16.80 \\
39.47 \\
28.57\end{array}$ \\
\hline $\begin{array}{l}\text { Gender } \\
\text { Male } \\
\text { Female }\end{array}$ & $\begin{array}{l}249 \\
190\end{array}$ & $\begin{array}{l}229 \\
156\end{array}$ & $\begin{array}{l}91.97 \\
82.11\end{array}$ & $\begin{array}{l}20 \\
34\end{array}$ & $\begin{array}{r}8.03 \\
17.89\end{array}$ \\
\hline $\begin{array}{l}\text { Mouthwash use } \\
>2 \text { times/day } \\
2 \text { times/day } \\
\text { About I time/day } \\
\text { About once every } 2 \text { days } \\
\text { I to } 2 \text { times/week } \\
<1 \text { time/week } \\
\text { Never }\end{array}$ & $\begin{array}{r}10 \\
59 \\
125 \\
36 \\
34 \\
78 \\
97\end{array}$ & $\begin{array}{r}9 \\
47 \\
104 \\
30 \\
31 \\
73 \\
91\end{array}$ & $\begin{array}{l}90.00 \\
79.66 \\
83.20 \\
83.33 \\
91.18 \\
93.59 \\
93.81\end{array}$ & $\begin{array}{r}1 \\
12 \\
21 \\
6 \\
3 \\
5 \\
6\end{array}$ & $\begin{array}{r}10.00 \\
20.34 \\
16.80 \\
16.67 \\
8.82 \\
6.41 \\
6.19\end{array}$ \\
\hline $\begin{array}{l}\text { Teeth loosened } \\
\text { No } \\
\text { Yes }\end{array}$ & $\begin{array}{r}395 \\
44\end{array}$ & $\begin{array}{r}364 \\
21\end{array}$ & $\begin{array}{l}92.15 \\
47.73\end{array}$ & $\begin{array}{l}31 \\
23\end{array}$ & $\begin{array}{r}7.85 \\
52.27\end{array}$ \\
\hline $\begin{array}{l}\text { Think have gum disease } \\
\text { No } \\
\text { Yes }\end{array}$ & $\begin{array}{r}387 \\
52\end{array}$ & $\begin{array}{r}349 \\
36\end{array}$ & $\begin{array}{l}90.18 \\
69.23\end{array}$ & $\begin{array}{l}38 \\
16\end{array}$ & $\begin{array}{r}9.82 \\
30.77\end{array}$ \\
\hline $\begin{array}{l}\text { Tooth not looking right } \\
\text { Never } \\
\text { Hardly ever } \\
\text { Sometimes } \\
\text { Fairly often } \\
\text { Very often }\end{array}$ & $\begin{array}{r}215 \\
49 \\
81 \\
29 \\
65\end{array}$ & $\begin{array}{r}194 \\
48 \\
69 \\
23 \\
51\end{array}$ & $\begin{array}{l}90.23 \\
97.96 \\
85.19 \\
79.31 \\
78.46\end{array}$ & $\begin{array}{r}21 \\
1 \\
12 \\
6 \\
14\end{array}$ & $\begin{array}{r}9.77 \\
2.04 \\
14.81 \\
20.69 \\
21.54\end{array}$ \\
\hline $\begin{array}{l}\text { Toothpick use past year } \\
>2 \text { times/day } \\
2 \text { times/day } \\
\text { About I time/day } \\
\text { About once every } 2 \text { days } \\
\text { I to } 2 \text { times/week } \\
<\text { l time/week } \\
\text { Never }\end{array}$ & $\begin{array}{r}3 \\
0 \\
8 \\
2 \\
7 \\
34 \\
385\end{array}$ & $\begin{array}{r}1 \\
0 \\
5 \\
2 \\
6 \\
23 \\
348\end{array}$ & $\begin{array}{r}33.33 \\
0.00 \\
62.50 \\
100.00 \\
85.7 \mid \\
67.65 \\
90.39\end{array}$ & $\begin{array}{r}2 \\
0 \\
3 \\
0 \\
1 \\
11 \\
37\end{array}$ & $\begin{array}{r}66.67 \\
0.00 \\
37.50 \\
0.00 \\
14.29 \\
32.35 \\
9.61\end{array}$ \\
\hline
\end{tabular}

* Model 2A displayed in Table 3. 
Table 6.

\section{Multivariable Logistic Regression Models Without Any Variables Forced for the Two Outcome Variables: NO_MODSEV (model 1A) and NOMOD_SEV (model 2A)}

\begin{tabular}{|c|c|c|c|c|c|c|c|c|c|c|}
\hline & \multicolumn{5}{|c|}{ Model IA (NO_MODSEV) } & \multicolumn{5}{|c|}{ Model 2A (NOMOD_SEV) } \\
\hline & \multicolumn{5}{|c|}{ No/Mild Versus Moderate or Severe $(\mathrm{N}=44 \mathrm{I})$} & \multicolumn{5}{|c|}{ No/Mild or Moderate Versus Severe $(N=439)$} \\
\hline & $\beta$ & SE & OR & $95 \% \mathrm{Cl}$ & $P$ Value* & $\beta$ & SE & OR & $95 \% \mathrm{Cl}$ & $P$ Value* \\
\hline \multicolumn{11}{|l|}{ Demographic variables } \\
\hline Age & 0.101 & 0.01 & 1.11 & 1.08 to 1.13 & $<0.001$ & 0.090 & 0.01 & 1.10 & 1.06 to 1.13 & $<0.001$ \\
\hline Gender & 0.557 & 0.26 & 1.75 & 1.06 to 2.88 & 0.030 & 1.498 & 0.41 & 4.47 & 2.02 to 9.92 & $<0.001$ \\
\hline Race & 0.709 & 0.27 & 2.03 & 1.21 to 3.42 & 0.008 & No & No & No & No & No \\
\hline Smoking & 0.748 & 0.27 & 2.11 & 1.24 to 3.60 & 0.006 & No & No & No & No & No \\
\hline \multicolumn{11}{|l|}{ Dental variables } \\
\hline Mouthwash use & No & No & No & No & No & -0.297 & 0.11 & 0.74 & 0.60 to 0.92 & 0.006 \\
\hline Painful gums & 0.310 & 0.13 & 1.36 & 1.05 to 1.77 & 0.020 & No & No & No & No & No \\
\hline Teeth loosened & No & No & No & No & No & 2.254 & 0.47 & 9.53 & 3.83 to 23.72 & $<0.001$ \\
\hline Think have gum disease & 1.452 & 0.39 & 4.27 & 1.99 to 9.18 & $<0.001$ & 1.062 & 0.50 & 2.89 & 1.09 to 7.65 & 0.032 \\
\hline Tooth not looking right & 0.321 & 0.09 & 1.38 & 1.16 to 1.64 & $<0.001$ & 0.404 & 0.13 & 1.50 & 1.17 to 1.92 & $<0.002$ \\
\hline Toothpick use past year & No & No & No & No & No & -0.392 & 0.16 & 0.68 & 0.50 to 0.92 & 0.012 \\
\hline
\end{tabular}

$\beta=$ coefficient; $\mathrm{SE}=$ standard error of $\beta$ coefficient; $\mathrm{OR}$ = odds ratio; $95 \% \mathrm{CI}=$ confidence interval; No = variable not included in model

* Probability for $\chi^{2}$ test.

examinations, we found statistically significant differences $(P<0.05)$ in responses to only one variable, i.e., smoking. Smokers among those with and without periodontal examinations were $31 \%$ versus $17 \%$, respectively. For the comparisons between participants with periodontal examinations and those who did not have visits for the in-home examination, 11 subjects were edentulous and were excluded from the comparisons. There were statistically significant differences between those with periodontal examinations and those without in-home examination visits for two variables: hurting teeth (25\% versus $10 \%$ percent reported "yes," respectively) and dental insurance status (10\% versus $4 \%$ reported having Medicaid, respectively). These findings of very few differences in the distributions of characteristics among the dentate participants with and without periodontal examinations provided support for selection bias being relatively inconsequential for the conclusions reached.

A strength of this study is that the distribution of the demographic characteristics of the sample was similar to the results from the 1990 United States Census for the Detroit tri-county area, ${ }^{37}$ suggesting that the sample was representative of the source population. Additionally, Waldrop ${ }^{38}$ reported that the Detroit tri-county area was representative of the United States population during the time that we conducted this survey. This demographic representativeness contributed to greater external validity and generalizability of the results.

An additional strength is that the entire study and, thus, all data collection instruments and methods, fo- cused exclusively on oral health. The in-home interview thoroughly assessed oral health self-care and professional care; attitudes, knowledge, and beliefs about oral health; risk behaviors related to oral health; and perceived barriers to oral health care. With each of the 455 respondents in this report also receiving a comprehensive oral examination, the data collected provided a unique opportunity to relate self-reported assessments to the objectively assessed clinical periodontal status of the respondents. This provided a valuable opportunity to test a comprehensive panel of self-report predictors of periodontal health.

\section{CONCLUSION}

Self-report may be valid for surveillance of periodontal disease burden and trends in the American population in lieu of more costly clinical periodontal examinations.

\section{ACKNOWLEDGMENTS}

This project was supported in part by National Institutes of Health/National Institute of Dental and Craniofacial Research (NIH/NIDCR) grant DE10145 and an appointment to the Research Participation Program for the CDC, National Center for Chronic Diseases Prevention and Health Promotion (NCCDPHP), Division of Oral Health (DOH), administered by the Oak Ridge Institute for Science and Education through an agreement between the Department of Energy and NCCDPHP. 
Table 7.

\section{Variable Name, Item Verbatim, and Response Categories for All Variables Appearing in the Five Candidate Models for Each of the Two Outcome Variables NO_MODSEV (Table 2) and NOMOD_SEV (Table 3)}

\begin{tabular}{|c|c|c|}
\hline Variable Name & Item Verbatim & Response Values \\
\hline Age & What are the month, day, and year of your birth? & Continuous whole integers $\geq 18$ to 93 \\
\hline Education & $\begin{array}{l}\text { What is the highest grade of school or year of college } \\
\text { you completed? }\end{array}$ & $\begin{array}{l}\text { I = none/ } \text { indergarten only; } 2=\text { grade } \mid \\
\text { to } 8 ; 3=\text { grade } 9 \text { to } \mid 1 ; 4=\text { grade } \mid 2 ; \\
5=\text { college } \mid \text { to } 3 \text { years; } \\
6=\text { college } \geq 4 \text { years }\end{array}$ \\
\hline Gender & None (No item asked. Face-to-face interviewer observation.) & 0 = female; 1 = male \\
\hline Income & $\begin{array}{l}\text { What was (yourlyour family's) total combined income in } 1993 \\
\text { before taxes, including salaries, wages, pensions, dividends, } \\
\text { interest, and all other family income? }\end{array}$ & Continuous whole integers \\
\hline Hurting teeth & Do you have any teeth that hurt? & $0=$ no; 1 = yes \\
\hline $\begin{array}{l}\text { Likely to get } \\
\text { gum disease }\end{array}$ & How likely is it that you will get gum disease? & $\begin{array}{l}\text { I = very likely; } 2 \text { = somewhat likely; } \\
\quad 3=50-50 \text { chance; } 4=\text { somewhat } \\
\text { unlikely; } 5 \text { = very unlikely }\end{array}$ \\
\hline Mouthwash use & How often do you use a mouthwash or any dental rinse product? & $\begin{array}{l}\mid=>2 \times / \text { day } ; 2=2 \times / \text { day; } 3=\mid \times / \text { day; } \\
4=1 \times / 2 \text { days; } 5=1 \text { to } 2 \times / \text { week; } \\
\quad=<\mid x / \text { week; } 7=\text { never }\end{array}$ \\
\hline Painful gums* & Have you had painful gums? & $\begin{array}{l}0=\text { never; } 1 \text { = hardly ever; } 2 \text { = sometimes; } \\
3 \text { = fairly often; } 4=\text { very often }\end{array}$ \\
\hline Race & $\begin{array}{l}\text { Do you consider yourself primarily white or Caucasian, } \\
\text { Black or African American, Asian or Pacific Islander, } \\
\text { or American Indian, Eskimo, or Aleut? }\end{array}$ & 0 = white; I = non-white \\
\hline Smoking & Do you smoke cigarettes? & $0=$ no; 1 = yes \\
\hline Teeth loosened & $\begin{array}{l}\text { Do you have any teeth that have gotten loose by themselves } \\
\text { without some injury? }\end{array}$ & $0=$ no; $1=$ yes \\
\hline $\begin{array}{l}\text { Think have } \\
\text { gum disease }\end{array}$ & $\begin{array}{l}\text { Another common problem with the mouth is gum disease. By gum } \\
\text { disease we mean any kind of problem with the gums around } \\
\text { your teeth that lasts for at least } 2 \text { weeks - except for problems } \\
\text { caused by injury or problems caused by partials or dentures. } \\
\text { Do you think you have gum disease? }\end{array}$ & $0=$ no; 1 = yes \\
\hline Tooth loss & $\begin{array}{l}\text { I) Other than wisdom teeth or teeth pulled to get braces, have } \\
\text { you lost any other teeth from your upper jaw? } \\
\text { 2) If yes to I): Have you lost all the teeth in your upper jaw? } \\
\text { 3) If no to I): Other than wisdom teeth or teeth pulled when } \\
\text { getting braces, about how many teeth have you lost from } \\
\text { your upper jaw? } \\
\text { (Same three questions for the lower jaw.) }\end{array}$ & $\begin{array}{l}\text { I = none; } 2=\mid \text { to } 5 \text { teeth; } 3=6 \text { to } 3 \mid \text { teeth; } \\
\quad 4=32 \text { teeth (categories for responses } \\
\text { to item verbatim } 3 \text { ) }\end{array}$ \\
\hline $\begin{array}{l}\text { Tooth not } \\
\text { looking right* }\end{array}$ & $\begin{array}{l}\text { Have you noticed a tooth which doesn't } \\
\text { look right? }\end{array}$ & $\begin{array}{l}0=\text { never; } 1 \text { = hardly ever; } 2 \text { = sometimes; } \\
3 \text { = fairly often; } 4 \text { = very often }\end{array}$ \\
\hline $\begin{array}{l}\text { Toothpick use } \\
\text { past year }\end{array}$ & How often have you used a soft triangular toothpick in the past year? & $\begin{array}{l}\mid=>2 \times / \text { day; } 2=2 \times / \text { day; } 3=\mid \times / \text { day; } \\
4=\mid \times / 2 \text { days; } 5=\mid \text { to } 2 \times / \text { week; } \\
6=<\mid \times / \text { week; } 7=\text { never }\end{array}$ \\
\hline
\end{tabular}

* OHIP items prefaced by "In the past three months,". 


\section{REFERENCES}

1. Eke PI. Public health implications of periodontal infections in adults: Conference proceedings. J Public Health Dent 2005;65:56-65.

2. Beck JD, Offenbacher S. The association between periodontal diseases and cardiovascular diseases: A stateof-the-science review. Ann Periodontol 2001;6:9-15.

3. Joshipura KJ, Hung H-C, Rimm EB, Willett WC, Ascherio A. Periodontal disease, tooth loss, and incidence of ischemic stroke. Stroke 2003;34:47-52.

4. Offenbacher S, Elter JR, Lin D, Beck JD. Evidence for periodontitis as a tertiary vascular infection. J Int Acad Periodontol 2005;7:39-48.

5. Paquette DW. The periodontal-cardiovascular link. Compend Contin Educ Dent2004;25:681-682, 685-692; quiz 694.

6. Offenbacher S. Maternal periodontal infections, prematurity, and growth restriction. Clin Obstet Gynecol 2004;47:808-821.

7. Xiong X, Buekens P, Fraser WD, Beck J, Offenbacher S. Periodontal disease and adverse pregnancy outcomes: A systematic review. BJOG 2006;113:135-143.

8. Taylor G. The effects of periodontal treatment on diabetes. J Am Dent Assoc 2003;134(10 Suppl.):41S-48S.

9. Janket SJ, Wightman A, Baird AE, Van Dyke TE, Jones JA. Does periodontal treatment improve glycemic control in diabetic patients? A meta-analysis of intervention studies. J Dent Res 2005;84:1154-1159.

10. Azarpazhooh A, Leake JL. Systematic review of the association between respiratory diseases and oral health. J Periodontol 2006;77:1465-1482.

11. Terpenning MS, Taylor GW, Lopatin DE, Kerr CK, Dominguez BL, Loesche WJ. Aspiration pneumonia: Dental and oral risk factors in an older veteran population. J Am Geriatr Soc 2001;49:557-563.

12. U.S. Department of Health and Human Services PHS. Healthy People 2010. Available at: http://www. healthypeople.gov/Publications/. Accessed February 21, 2007.

13. Centers for Disease Control and Prevention (CDC). Behavioral Risk Factor Surveillance System Survey Questionnaire 2006. Available at: http://www.cdc.gov/ brfss/questionnaires/pdf-ques/2006brfss.pdf. Accessed December 6, 2006.

14. Nelson DE, Holtzman D, Bolen J, Stanwyck CA, Mack KA. Reliability and validity of measures from the behavioral risk factor surveillance system (BRFSS). Soz Präventiumed 2001;46(Suppl. 1):S3-S42.

15. Blicher B, Joshipura K, Eke P. Validation of selfreported periodontal disease: A systematic review. $J$ Dent Res 2005;84:881-890.

16. Dietrich T, Stosch U, Dietrich D, Schamberger D, Bernimoulin JP, Joshipura K. The accuracy of individual self-reported items to determine periodontal disease history. Eur J Oral Sci 2005;113:135-140.

17. Borrell LN, Taylor GW, Borgnakke WS, et al. Factors influencing the effect of race on established periodontitis prevalence. J Public Health Dent 2003;63:20-29.

18. Lang WP, Borgnakke WS, Taylor GW, Woolfolk MW, Ronis DL, Nyquist LV. Evaluation and use of an index of oral health status. JPublic Health Dent 1997;57:233-242.

19. Ronis DL, LangWP, Antonakos CL, BorgnakkeWS. Preventive oral health behaviors among African-Americans and whites in Detroit. J Public Health Dent 1998;58:234-240.

20. Slade GD, Spencer AJ. Development and evaluation of the Oral Health Impact Profile. Community Dent Health 1994;11:3-11.
21. Locker D. Measuring oral health: A conceptual framework. Community Dent Health 1988;5:3-18.

22. Miller AJ, Bruneller JA, Carlos JP, Brown LJ, Löe H. Oral Health of United States Adults: The National Survey of Oral Health in US Employed Adults and Seniors, 1985 1986 - National Findings. Washington, DC: U.S. Department of Public Health and Human Services, Public Health Services, National Institutes of Health; 1987:161-165.

23. Page RC, Eke PI. Case definitions for use in population-based surveillance of periodontitis. J Periodontol 2007;78:1387-1399.

24. Swets JA. Measuring the accuracy of diagnostic systems. Science 1988;240:1285-1293.

25. Ekanayake L, Perera I. The association between clinical oral health status and oral impacts experienced by older individuals in Sri Lanka. JOral Rehabil 2004;31:831-836.

26. Fernandes MJ, Ruta DA, Ogden GR, Pitts NB, Ogston SA. Assessing oral health-related quality of life in general dental practice in Scotland: Validation of the OHIP 14. Community Dent Oral Epidemiol 2006;34:53-62.

27. Ikebe K, Watkins CA, Ettinger RL, Sajima H, Nokubi T. Application of short-form oral health impact profile on elderly Japanese. Gerodontology 2004;21:167-176.

28. John MT, Patrick DL, Slade GD. The German version of the Oral Health Impact Profile -Translation and psychometric properties. Eur J Oral Sci 2002;110:425-433.

29. Kushnir D, Zusman SP, Robinson PG. Validation of a Hebrew version of the Oral Health Impact Profile 14. $J$ Public Health Dent 2004;64:71-75.

30. Larsson P, List T, Lundstrom I, Marcusson A, Ohrbach R. Reliability and validity of a Swedish version of the Oral Health Impact Profile (OHIP-S). Acta Odontol Scand 2004;62:147-152.

31. Oliveira BH, Nadanovsky P. Psychometric properties of the Brazilian version of the Oral Health Impact Profile-Short form. Community Dent OralEpidemiol2005;33:307-314.

32. Saub R, Locker D, Allison P. Derivation and validation of the short version of the Malaysian Oral Health Impact Profile. Community Dent Oral Epidemiol 2005;33:378-383.

33. Savolainen J, Suominen-Taipale AL, Hausen H, et al. Sense of coherence as a determinant of the oral health-related quality of life: A national study in Finnish adults. Eur J Oral Sci 2005;113:121-127.

34. Segu M, Collesano V, Lobbia S, Rezzani C. Crosscultural validation of a short form of the Oral Health Impact Profile for temporomandibular disorders. Community Dent Oral Epidemiol 2005;33:125-130.

35. Slade GD, Spencer AJ, Locker D, Hunt RJ, Strauss RP, Beck JD. Variations in the social impact of oral conditions among older adults in South Australia, Ontario, and North Carolina. J Dent Res 1996;75:1439-1450.

36. Wong MC, Lo EC, McMillan AS. Validation of a Chinese version of the Oral Health Impact Profile (OHIP). Community Dent Oral Epidemiol 2002;30:423-430.

37. Bureau of the Census. 1990 Census of Population and Housing: Summary Population and Housing Characteristics. Washington, DC: Bureau of the Census; 1991.

38. Waldrop J. All-American markets. Am Demogr 1992; 14:24-27,30.

Correspondence: Dr. George W. Taylor, Department of Cariology, Restorative Sciences, and Endodontics, University of Michigan School of Dentistry, 1011 N. University Ave., Ann Arbor, MI 48109-1078. Fax: 734/936-1597; e-mail: gwt@umich.edu.

Accepted for publication February 24, 2007. 